Research Article

\title{
EXPRESSION PROFILING OF ZINC TRANSPORTER GENES IN TOMATO GROWN UNDER DIFFERENT CONCENTRATIONS OF ZINC
}

\author{
BASAVARAJESHWARI R.M. ${ }^{1}$, YAMUNARANI R. ${ }^{2}$, RAMEGOWDA V. ${ }^{2}$, GEETHA K.N. ${ }^{3}$ AND SHANKAR A.G. ${ }^{* 2}$ \\ ${ }^{1}$ Division of Plant Physiology and Biochemistry, ICAR-Indian Institute of Horticultural Research, Hessaraghatta lake post, Bengaluru, 560089, Karnataka, India \\ 2Department of Crop Physiology, University of Agricultural Sciences, GKVK, Bengaluru, 560065, Karnataka, India \\ ${ }^{3}$ Department of Agronomy, University of Agricultural Sciences, GKVK, Bengaluru, 560065, Karnataka, India \\ *Corresponding Author: Email- ambara8@hotmail.com
}

Received: June 07, 2018; Revised: June 15, 2018; Accepted: June 16, 2018; Published: June 30, 2018

\begin{abstract}
Zinc is an important micronutrient required for various biological processes in plants and animals. To improve zinc uptake of plants it is essential to understand the molecular and physiological mechanisms underlying zinc uptake process. Hence, in the present study expression analysis of zinc transporter genes and zinc accumulation in tomato at three different zinc treatments was assessed. Expression profiles showed LeZIP1, LeZIP3, LeZIP5 and LeZIP6 as low zinc responsive zinc transporter genes and LeZIP2 as a high zinc responsive gene. Quantitative real time expression analysis showed 1.5 and 1.8 fold decrease in transcript levels of LeZIP2 in excess zinc and deficient zinc treatments, respectively. Estimation of zinc content in leaves and roots of these zinc treated plants showed significant increase in zinc content of zinc deprived plants upon providing moderate zinc. Zinc content in leaves and roots increased with the increase in the external zinc application. Thus, different zinc contents in plant parts could be attributed to differential expression of zinc transporter genes.
\end{abstract}

Keywords- Zinc transporters, zinc deficiency, biofortification, differential expression and ZIP genes

Citation: Basavarajeshwari R.M., et al., (2018) Expression Profling of Zinc Transporter Genes in Tomato Grown Under Different Concentrations of Zinc. International Journal of Microbiology Research, ISSN: 0975-5276 \& E-ISSN: 0975-9174, Volume 10, Issue 6, pp.-1252-1255.

Copyright: Copyright@2018 Basavarajeshwari R.M., et al., This is an open-access article distributed under the terms of the Creative Commons Attribution License, which permits unrestricted use, distribution and reproduction in any medium, provided the original author and source are credited.

Academic Editor / Reviewer: Vinod S Kukanur

\section{Introduction}

Zn plays a part in the basic roles of cellular functions in all living organisms including plants and animals. Unfortunately, $50 \%$ of the agricultural soils around the world are at risk of medium zinc deficiency, which might progress into a widespread deficiency in the coming years. In India around 80 Mha of agricultural land is zinc deficient [1]. Soil zinc deficiency in turn results in zinc deficient crops that are grow on such soils. It is also reported that as much as $30 \%$ of the world's population is at risk of zinc deficiency [2]. Thus, addressing the issue of the zinc deficiency of soil-plant-human continuum is essential. Various interventions to curb zinc deficiency such as supplementation, fortification etc., are not cost effective [3] and sustainable. Thus, biofortification of crops is the most cost effective [3] and preventative measure to fight human zinc deficiency. Many laboratories are currently pursuing biofortification using breeding and genetic modification approaches. Efforts in this area are being made, like screening for zinc efficient genotypes [4-8] and subsequently employing them to breed for zinc efficient genotype. While in genetic modification approach, cloning of the high affinity zinc transporters [9] and overexpressing them into the crop plants [10-12] to improve crop zinc status is being attempted. In order to select, the candidate genes for overexpression in the plant system, molecular and physiological mechanisms underlying zinc uptake and translocation need to be studied in detail. Several studies are available in different crops [13-16] but little is known about the physiological mechanisms of differential zinc efficiency in tomato, hence this experiment was conducted to know the zinc homeostasis process in tomato.

\section{Material and Methods}

Plant material and zinc treatment

Tomato seeds of Pusa Ruby were sown and seedlings were raised in small plastic pots containing soilrite. These plants were irrigated with half strength MS media thrice a week to provide all essential nutrients. Fourteen days after sowing, the plants were subjected for different levels of zinc. Different sets of plants were maintained at three different zinc status viz., without zinc, moderate zinc $(15 \mu \mathrm{M})$ and excess zinc $(100 \mu \mathrm{M})$. These treatments were imposed using half strength Hogland's solutions; without zinc, $15 \mu \mathrm{M}$ zinc and $100 \mu \mathrm{M}$ zinc, respectively. The micronutrient stock of Hogland solutions was prepared by dissolving all the micronutrients in recommended concentrations excluding zinc. For $15 \mu \mathrm{M}$ and $100 \mu \mathrm{M}$ zinc treatments, additional zinc $\left(\mathrm{ZnSO}_{4} 7 \mathrm{H}_{2} \mathrm{O}\right)$ were added by calculating the amount of $\mathrm{ZnSO}_{4}$ required for given volume of Hogland solutions prepared. The plants were maintained with the respective treatments in two sets. One set was harvested to see the treatment effect after treatment and second set was to see the treatment effect after recovery. First set was harvested 15 days after treatment imposition and again half strength Hogland solutions with all nutrients was given for another 15 days. In the first and second set, the roots and shoots of the respective treatments were collected to study the differential expression of zinc transporter genes. The samples were also collected in each treatment for estimation of zinc.

Zinc estimation in leaf and root samples grown under different zinc levels Leaves and roots were ground with pestle and mortar to a fine powder. Five $\mathrm{mL}$ of concentrated nitric acid $\left(\mathrm{HNO}_{3}\right)$ was added to $0.25 \mathrm{~g}$ of powdered sample and incubated in a digestion hood overnight. The next day, $5 \mathrm{~mL}$ of diacid mixture (Nitric: Perchloricacid:: 10:4) was added and placed on a sand bath till all the white fumes evaporated and a colourless liquid was left in the flask. It was allowed to cool and volume was made up to $100 \mathrm{~mL}$ using glass distilled water and further dilutions were made if the concentration of the samples was too high. 
These diluted samples were used for zinc estimation. Zinc was estimated in the samples using polarized Zeeman Atomic Absorption Spectrophotometer (AAS-26100). The zinc content was calculated using the below formula and zinc content was expressed as $\mathrm{mg} / 100 \mathrm{~g}$ of sample.

$$
\text { zinc content }=\frac{\text { Average } p p m \times \text { volume made up }}{10^{6} \times \text { weight of the sample }}
$$

\section{RNA extraction and RT-PCR analysis}

RNA was isolated to know the differential expression of zinc transporters under different zinc treatment, following the protocol of [17] with some modifications. The concentration of the extract was quantified spectrophotometrically (UV-2450, Shimadzu corporation, Japan) at $260 \mathrm{~nm}$. The quality of the extraction was ascertained by measuring the OD at $260 / 280 \mathrm{~nm}$ and confirmed by agarose gel fractionation (with ethidium bromide staining) and visualized under UV light. The RNA was reverse transcribed to CDNA using reverse transcriptase (MMLV-RT, $\mathrm{MBI}$ Fermentas, Germany) using standard protocol. The cDNA was used as a template for PCR amplification. The sequence information of well-characterized ZIP transporters in Arabidopsis was used as base information to perform BLAST analysis in tomato genome. Five zinc transporters were selected for the study. The five primers sequence used for PCR has been given in Table-1 along with the locus ID. Amplification was performed under standardized conditions in Thermo cycler. Electroporation of PCR amplified products were done on $1.0 \%$ agarose gel using TAE buffer of $1 \mathrm{X}$ concentration and was stained with ethidium bromide. The agarose gel was visualized under UV-transilluminator.

\section{Quantitative Real Time PCR analysis}

First strand cDNA was synthesized from total RNA (200 ng) by oligo (dT) 15 priming using Molony Murine Leukaemia Virus reverse transcriptase enzyme (MMuLV-RT; MBI Fermentas). The CDNA pool was used as a template to perform quantitative real time PCR (Opticon2, MJ research, USA) and the log linear phase was set at 30 cycles. Real-time PCR was performed in the presence of the fluorescent dye SYBR-green (DyNAmo SYBR-green qPCR Kit FiNNZYMES, Finland) following the manufacturer's protocol. The Ct value (the fractional cycle number at which fluorescence passes a fixed threshold) was used to compare the target RNA in the sample. The calculations were performed as described in manufacturer's protocol. The abundance of gene was normalized to the level of constitutively expressed gene, Actin.

\section{Statistical analysis}

The zinc content in roots and shoots were expressed as mean and standard error $(\mathrm{M} \pm \mathrm{SE})$ and MSATAC software used to analyse data.

\section{Results \\ Assessment of leaf and root zinc content in tomato under different zinc levels \\ To study the effect of external zinc application on zinc content in tomato, zinc concentrations were estimated in roots and leaves as a measure of uptake and translocation under different levels of zinc. The pattern of zinc distribution varied between the treatments [Fig-1]. In plants subjected to deficient zinc, the zinc content increased significantly in both root and shoot upon moderate zinc application. The plants that were treated with moderate and excess zinc had no significant changes in their leaf and root zinc content with the application of moderate zinc treatment. Irrespective of the zinc treatments, the root zinc content was higher than the leaf zinc content in all the plants. The zinc content was greatest in excess zinc treated plants followed by moderate zinc treated plants and deficient zinc treated ones. The deficient zinc treated plants subjected to recovery has accumulated zinc, which was on par with the zinc content in the moderate plants. With the increase in concentration of zinc application the leaf and root zinc content also increased linearly. \\ Transcript levels of zinc transporter genes at different levels of zinc treatment \\ Differential expression was observed for all the zinc transporter genes in tomato}

plants subjected to different zinc concentrations. Expression of LeZIP1, LeZIP5 and LeZIP6 transcripts was not observed during early cycles of PCR but the transcript levels increased gradually with the increase in PCR cycles and expression was found to be higher under zinc deficient conditions. LeZIP3 showed an early expression in moderate and deficient zinc treatments and at the end of 30 PCR cycles there was a weak expression of LeZIP3 in zinc excess conditions and increased expression in moderate and deficient zinc conditions. But LeZIP2 showed entirely different expression profile. There was greater expression of LeZIP2 under excess zinc conditions in 30 cycles of PCR, while there was no significant level of expression observed at early cycles of PCR for LeZIP2 [Plate1]. After 15 days of treatment imposition, the plants were subjected to recovery by providing moderate zinc. The genes LeZIP1, LeZIP5 and LeZIP6, which showed increased expression under zinc deficient conditions, had decreased after these plants were subjected to recovery. While LeZIP3 showed no such difference in expression after recovery. In contrast, LeZIP2 transcripts increased after recovery in zinc deprived plants compared to its expression, which was captured after zinc treatment [Plate-1].

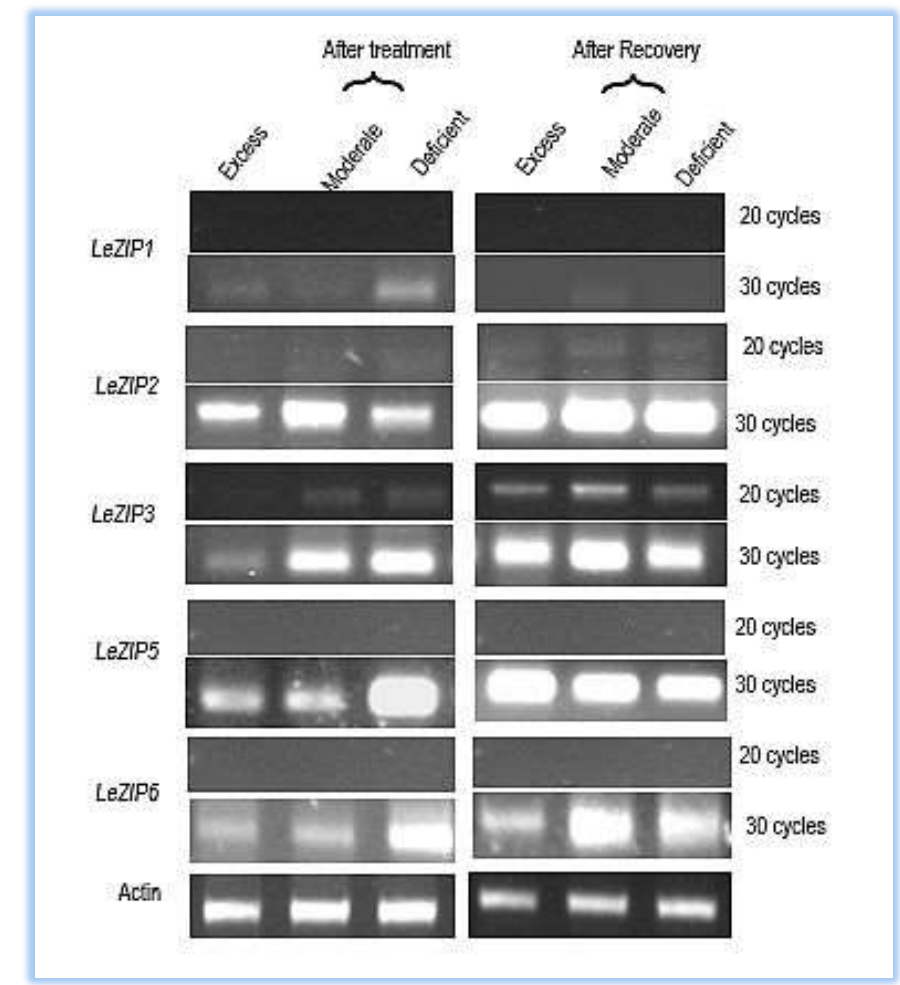

Plate-1 Expression analysis of tomato zinc transporters under different levels of zinc treatment by Semi-Quantitative RT PCR

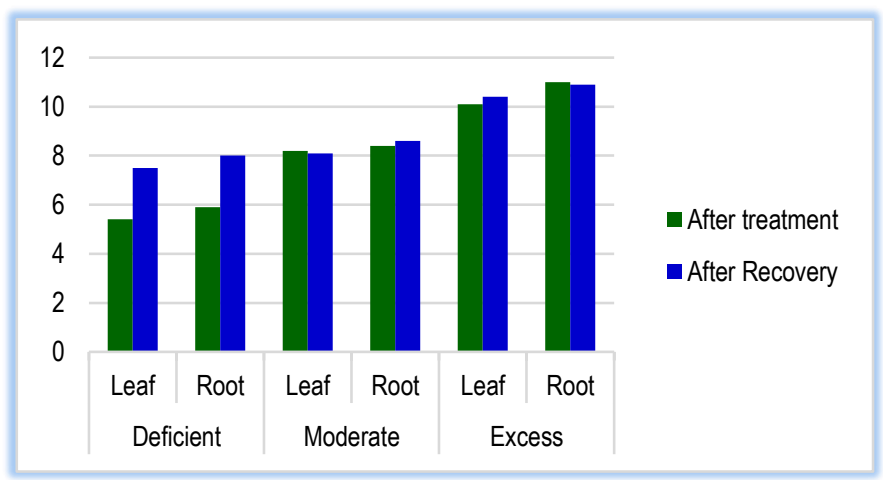

Fig-1 Zinc content in leaves and roots of tomato plants under different zinc treatments

To validate the results of RT-PCR analysis, expression of LeZIP2 at different zinc treatments was assessed by quantitative Real time PCR analysis. Amplification of the right product was confirmed through melting curve analysis. Melting temperature of amplicon was $81^{\circ} \mathrm{C}$, which was equal to calculated $\mathrm{Tm}$ of the product [Fig-2a]. 
Relative change in gene expression over moderate zinc treatment was calculated [Fig-2b]. Relative change in expression showed that there was 1.5 fold decrease in transcript levels of excess zinc treatment over the moderate zinc treatment. While there was 1.8 fold decrease in transcript levels of zinc deficient treatment over the moderate zinc treatment [Fig-2c].

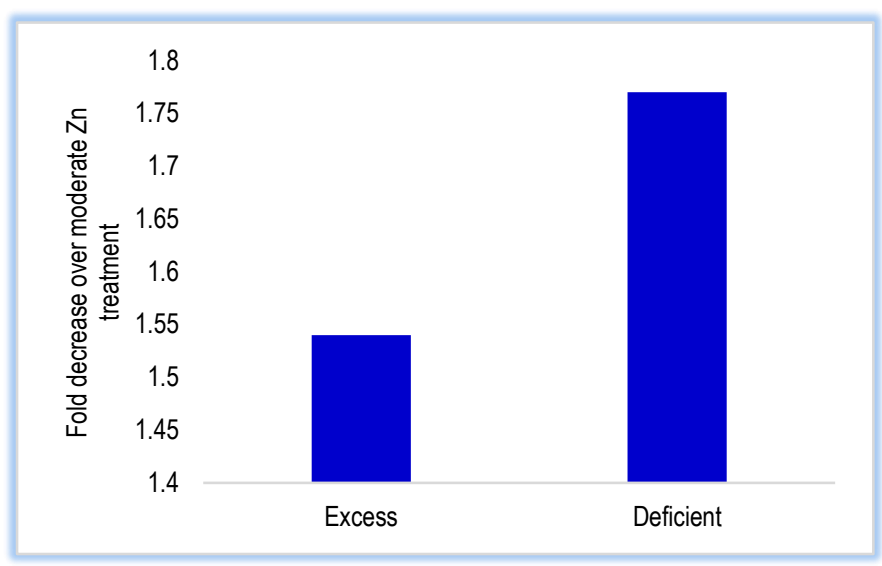

Fig-2a

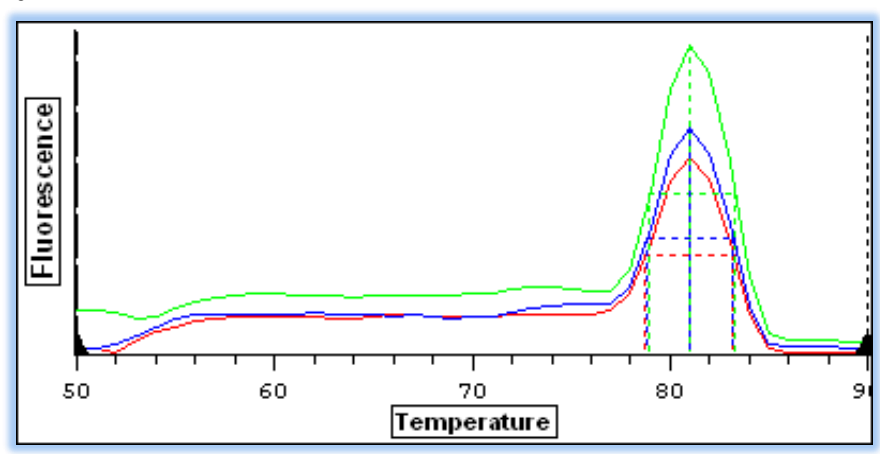

Fig-2b

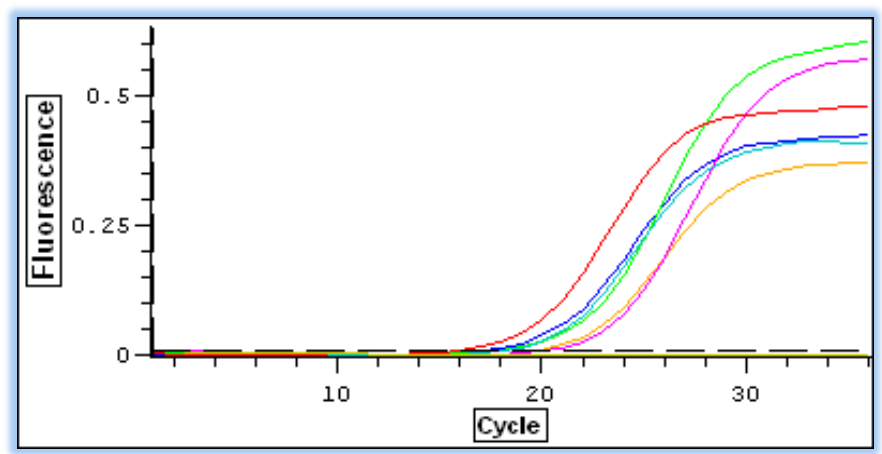

Fig-2c

Fig-2 Quantitative Real Time PCR analysis of LeZIP2 (a) Graph showing fold decrease of LeZIP2 transcripts (b) Graph showing C(T) values of LeZIP2 (c) Melting curve of LeZIP2

\section{Discussion}

The present study was conducted to understand the expression profile of zinc transporter genes and zinc distribution in roots and shoots in tomato grown under different levels of zinc. The tomato variety Pusa Ruby showed varied responses to deficient, moderate and excess levels of zinc, which was evident by variations in zinc contents in roots and shoots of respective treatments [Fig-1]. Our results demonstrated that with the increase in concentration of applied zinc, the zinc content in plant plants also increased. In moderate zinc treatment the zinc content in shoots and roots increased to $57 \%$ and $87 \%$ respectively compared to deficient zinc treatment, while the increase in zinc in excess zinc treated plants was $42 \%$ in shoot and $83 \%$ in root. However, the increased zinc content did not compliment the growth of the tomato seedlings. The shoot and root length were affected under deficient and excess zinc conditions, while it was significantly higher in moderate zinc treatment [Table-2]. Malik, et al., 2011 [18], reported that there was gradual increase of zinc concentration in amaranth and rice seedlings with the increasing zinc levels. They also reported that shoot and root length gradually decreased with increasing treatment of zinc and the length was lowest at 400 ppm zinc. Similarly, there are studies showing adverse effect of excess zinc on plant growth $[19,20]$. When tomato plants were subjected to recovery treatment with moderate zinc application, zinc content did not vary much in moderate and excess zinc treated plants but significant increase in zinc in root and leaves of zinc-deprived plants was observed. This variation in zinc content in different plant parts might be attributed to differential expression of zinc transporters under different zinc treatments. Previous studies that support the data have shown that increased mRNA abundance of a zinc transporter was associated with increased uptake in the root cells of hyperaccumulator Thlaspi caerulescens [21, 22]. Several members of the ZIP family of zinc and iron transporters in Escherichia coli [23], Saccharomyces cerevisiae [24], plants [1316], and humans [25] have been well studied. In plants, ZIP transporters have been widely studied in dicots such as Pisum sativa, Arabidopsis, and $T$. caerulescens. Conversely, there is partial information available on zinc transporters in tomato. Hence, five zinc transporter genes of ZIP family were identified using TAIR and NCBI GenBank and used to evaluate their expression signature in tomato so that the variation in zinc content at different zinc levels could be correlated. Our expression data in tomato showed that transcript levels of LeZIP1, LeZIP5 and LeZIP6 were higher under zinc deficient conditions. LeZIP3 transcripts were detectable under moderate and deficient zinc conditions. However, transcripts levels of LeZIP2 were higher in moderate zinc conditions compared to zinc deficient conditions. Quantitative Real Time PCR analysis showed that there was 1.5 fold decrease in transcript levels of LeZIP2 under excess zinc conditions over the moderate zinc treatment. Several members of ZIP family transporters have been characterized and shown to be involved in zinc uptake and transport mechanism in plants. Many expression studies have shown that several members of ZIP transporters were induced under zinc deficiencies in Arabidopsis [26]. OsZIP1, OsZIP3, OsZIP4, OsZIP5, and OsZIP8 are rice plasma membrane zinc transporters and are induced by zinc deficiency [27, 28]. Transcript levels of ZIP1 of Arabidopsis were shown to be up-regulated in leaves under zinc deficient condition. However, expression of ZIP1 was not detectable in roots under sufficient or excess zinc conditions though it is localized to both the roots and leaves in rice [29]. However, ZIP2 and ZIP7 in Arabidopsis showed enhanced expression in leaves with the application of zinc [30]. Hence, in our study LeZIP1, LeZIP3, LeZIP5 and LeZIP6 are high affinity Zinc transporters induced under deficient zinc condition while LeZIP2 is a low affinity Zinc transporter expressed under excess zinc conditions. Apart from the zinc concentration as a factor, several other factors also influence the accumulation of zinc in plants. Such as, the expression of most of the well-studied rice ZIP genes (OsZIP1,0sZIP4,0sZIP5) was controlled by the availability of divalent cations viz., $\mathrm{Zn} 2+, \mathrm{Fe} 2+, \mathrm{Cu} 2+, \mathrm{Mn} 2+$. Few studies also confirmed that these transporter genes' expression profiles were diverse between root and shoot tissues of rice [31]. Similarly, Chen, et al., 2008 [32] reported the differential expression pattern of ZIP genes (OsZIP1, OsZIP3, and OsZIP4) between zinc-efficient and zinc-inefficient cultivars of rice. Hence, a multi-dimensional study to understand the zinc uptake mechanism will give a better insight in zinc uptake and translocation mechanisms in plants which can be exploited to improve zinc nutrition in both plants and animals.

\section{Conclusion}

The study signifies the essentiality of zinc as a micronutrient at its optimum concentration beyond which it has adverse effects on tomato growth. It also provides information on differential expression of zinc transporters in tomato regulating the accumulation of zinc under different zinc levels. The semi quantitative RT- PCR data projected that LeZIP1, 3, 5 and 6 are high affinity zinc transporters and LeZIP2 is a low affinity zinc transporter.

This information provides an insight into different types of zinc transporter genes and use of high affinity zinc transporters in overexpression studies in tomato to improve the zinc nutrient concentrations in tomato. 
Application of research: Putative high affinity zinc transporters have been identified. This information can be used for functional validation of the identified genes.

Research Category: Plant nutrition, Crop Physiology

Abbreviations:

ZIP: Zrt Zinc transporter protein

Irt: Iron transporter protein-like protein

RT-PCR: Reverse transcriptase - Polymerase Chain Reaction

Acknowledgment / Funding: The authors wish to thank Department of Crop Physiology, University of Agricultural Sciences, GKVK, Bengaluru, 560065, Karnataka for providing facilities to carry out the experiment.

\section{*Principle Investigator: Professor Dr A G Shankar}

University: University of Agricultural Sciences, Bengaluru, 560065, Karnataka

Research project name or number: MSc Research

\section{Author Contributions: All author equally contributed}

Author statement: All authors read, reviewed, agree and approved the final manuscript

\section{Conflict of Interest: None declared}

Ethical approval: This article does not contain any studies with human participants or animals performed by any of the authors.

\section{References}

[1] Alloway B. J. (2008) Second edition, IZA and IFA Brussels, Belgium and Paris, France.

[2] Welch R.M. (2002) Plant and Soil, 247, 83-90.

[3] Stein A.J., Nestel P., Meenakshi J. V. and Qaim M. (2006) Public Health Nutrition, 10 (5), $492-501$.

[4] Yamunarania R., Geetha G., Ramegowdaa V., Harshavardhan V. T. and Shankar A. G. (2016) The Crop Journal 4, 229-234.

[5] Nagarathna T. K., Shankar A. G. and Udayakumar M. (2010) Journal of Agriculture Technology, 6, 171-178.

[6] Gregorio G.B., Senadhira D., Htut T. and Graham R.D. (2000) Food Nutrition Bulletin, 21, 382-386.

[7] Beebe S., Gonzalez A.V. and Rengifo J. (2000) Food Nutrition Bulletin, 21, 387-391.

[8] Basavarjeshwari R.M. (2016) PhD thesis, Department of Crop Physiology, UAS, GKVK Bengaluru.

[9] Mathapati B.R., Yamunarani R., Geetha K. N. and Shankar A. G. (2015) International Journal of Bio-resource and Stress Management, 6(3), 396-401.

[10] Basavarajeshwari R. M., Yamunarani R., Ramegowda H. V., Geetha, K. N. and Shankar A. G. (2015) Environment and Ecology, 33 (4B), 1955-1959.

[11] Yamunarani R., Venkategowda R., Jagadish P., Govind G., Reddy R. H., Makarla, U. and Guligowda S. A. (2013) Plant Biotechnology Reports, 7, 309-319.

[12] Lee S. and An G. (2009) Plant Cell Environment, 32,408-416.

[13] Grotz N., Fox T., Connolly E., Park W., Guerinot M. L. and Eide, D. (1998) Proceedings of the National Academy of Sciences, 95, 72207224.

[14] Guerinot M. L. (2000) Biochimica et Biophysica Acta, 1465, 190-198.

[15] Vert G., Briat J. F. and Curie C. (2001) The Plant Journal, 26, 181-189.

[16] Moreau S., Thomson R. M., Kaiser B. N., Trevaskis B., Guerinot M. L., Udvardi M. K., Puppo A. and Day D. A. (2002) Journal of Biological Chemistry, 15, 4738-4746.
[17] Datta K., Schmidt A. and Marcus A. (1989) Plant Cell, 1, 945-952.

[18] Malik N. J., Chamon A. S., Mondol M. N., Elahi S. F. and Faiz S. M. A. (2011) Journal of the Bangladesh Association of Young Researchers (JBAYR), 1(1), 79-91.

[19] Ali M. R., Mehrajb H. and Jamal Uddinc A. F. M. (2015) Journal of Bioscience and Agriculture Research, 6(1), 512-517.

[20] Hanan E. I. and Said D. (2008) Academic Journal of Plant Sciences, 1 (1), 05-11.

[21] Lasat M. M., Pence N. S., Garvin D. F. Ebbs S. D. and Kochian L.V. (2000) Journal of Experimental Botany, 51, 71-79.

[22] Pence N. S., Larsen P. B., Ebbs S. D., Letham D. L., Lasat M. M., Garvin D. F., Eide D. and Kochian L. V. (2000) Proceedings of the National Academy of Sciences, 97, 4956-4960.

[23] Grass G., Wong M. D., Rosen B. P., Smith R. L. and Rensing C. (2002) Journal of Bacteriology, 184, 864-866.

[24] Zhao H. and Eide D. (1996) The Journal of Biological Chemistry, 271, 23203-23210.

[25] Gaither L. A. and Eide D. J. (2001) Biometals, 14, 251-270.

[26] Wintz H., Fox T., Wu Y. Y., Feng V., Chen W., Chang H. S., Zhu T. and Vulpe C. (2003) Journal of Biological Chemistry, 28, 47644 47653 .

[27] Lee S., Kim S., Lee J., Guerinot M. and AnG. (2010) Molecules and Cells, 29,551-558.

[28] Suzuki M., Bashir K., Inoue H., Takahashi M., Nakanishi H. and Nishizawa N. (2012) Rice, 5, 1-8.

[29] Ramesh S. A., Shin R., Eide D. J. and Schachtman D. P., (2003) Plant Physiology, 133,126-134.

[30] Ramesh S. A., Choimes S. and Schachtman D. P. (2004) Plant Molecular Biology, 54, 373-385.

[31] Ishimaru Y., Bashir K. and Nishizawa N. (2011) Rice, 4, 21-27.

[32] Chen W. R., Feng Y. and Chao Y. E. (2008) Russian Journal of Plant Physiology, 55, 400-409. 